\title{
Value of routine sinus radiography in the diagnostic work-up of ill returned travelers: critical appraisal in a cohort of 765 travelers
}

This article was published in the following Dove Press journal:

International Journal of General Medicine

I I April 201 I

Number of times this article has been viewed

\author{
Carla Moolenaar' \\ Perry J van Genderen ${ }^{2,3}$ \\ 'Department of Radiology, Harbour \\ Hospital, ${ }^{2}$ Institute for Tropical \\ Diseases, ${ }^{3}$ Travel Clinic, Harbour \\ Hospital, Rotterdam
}

\begin{abstract}
Background: Upper respiratory tract problems, eg, acute sinusitis are frequently occurring illnesses in returned travelers. The most accurate and cost-effective method for diagnosing these upper respiratory tract illnesses in hospital-based settings remains an area of uncertainty. In the present retrospective cohort study, the usefulness of routine sinus radiography in the diagnostic work-up of ill returned travelers was evaluated.

Methods: This study was done at the Institute for Tropical Diseases in Rotterdam, and included all returned travelers who were ill with symptoms lasting less than one month in the period 2007-2009 and had sinus radiography on admission. Traveler demographic (including travel history), clinical, and laboratory data were collected on admission, and sinus radiography findings evaluated for their diagnostic power to predict sinusitis.

Results: One hundred and sixty-five (22\%) of 765 ill returned travelers had abnormal sinus radiography; more than half of the abnormal radiographic findings comprised mucosal membrane thickening of the sinuses. More than half of the travelers with abnormal sinus radiography had no upper respiratory tract symptoms at admission, which raises doubt about the clinical relevance of abnormal radiographic findings. Travelers with abnormal sinus radiography were more likely to receive nasal decongestants (relative risk 18.2, confidence interval 9.4-35.1) but not antibiotics.
\end{abstract}

Conclusion: The results of the present study indicate that there is no additional value for routine sinus radiography in the diagnostic work-up of ill returned travelers.

Keywords: traveler, illness, sinusitis, fever, radiography

\section{Introduction}

Acute rhinosinusitis is a common diagnosis in primary care settings, with a prevalence of 27.4 per 1000 per year. ${ }^{1}$ Acute rhinosinusitis can exist as either a purulent or a serous sinusitis, and only purulent sinusitis is thought to benefit from antibiotic treatment. ${ }^{2,3}$ Even though sinus puncture is considered to be the "gold standard" for acute purulent sinusitis, its inconvenience and associated patient discomfort precludes its use as a widely accepted diagnostic tool. ${ }^{4}$ A systematic review evaluating the value of ultrasound, radiography, and clinical examination in the diagnosis of acute maxillary sinusitis found that, compared with sinus puncture, radiography was the most accurate method for diagnosing acute maxillary sinusitis. ${ }^{5}$ However, the diagnostic performance of sinus radiography and other imaging techniques is questioned in primary care settings. ${ }^{1}$ As a consequence, current guidelines for general practitioners follow a symptom-based approach for the diagnosis of acute sinusitis. ${ }^{1}$
Correspondence: Perry J van Genderen Institute for Tropical Diseases,

Harbour Hospital, Haringvliet 72,

30I I TG Rotterdam,

The Netherlands

Tel +3। 104043305

Fax +31 104121645

Email p.van.genderen@havenziekenhuis.nl 
Interestingly, each year, up to $8 \%$ of the more than 50 million travelers from industrialized countries to developing countries, representing four million persons, are ill enough to seek health care, either while abroad or on returning home. ${ }^{6}$ In general, upper respiratory tract problems, like acute sinusitis, are among the most frequently occurring illnesses in returned travelers, and estimates suggest a prevalence of 77 per 1000 ill returned travellers. ${ }^{6}$ However, the most accurate method for diagnosing these upper respiratory tract illnesses remains an area of uncertainty in hospital-based settings.

At the Institute for Tropical Diseases in Rotterdam, The Netherlands, ill returned travelers are evaluated following a standardized diagnostic protocol, which includes routine sinus radiography. In this retrospective cohort study, the usefulness of routine sinus radiography in the diagnostic work-up of ill returned travelers was evaluated.

\section{Methods}

The Harbour Hospital is a 161-bed general hospital located in Rotterdam, The Netherlands. It also harbors the Institute for Tropical Diseases, which serves as a national referral center for tropical diseases. All travelers who returned ill with acute symptoms (ie, lasting less than one month) and who had sinus radiography on admission were included in this study. For each traveler, demographic (including travel history), clinical, and laboratory data on admission were collected, as well as the findings of sinus radiography. All data were stored in an electronic database in a way that the data could not be linked back to an individual patient. All laboratory measurements were performed using standard laboratory techniques. Sinus radiography was performed in three directions, ie, the frontonasal posterior anterior (PA) view, occipitomental PA view (Water's view) and lateral view, respectively. Radiographic findings compatible with acute sinusitis were described as "opacity", "mucus membrane thickening", and "fluid level", or as a combination of these.

\section{Statistical analysis}

All values are presented as median (range). Comparison between groups was made with the nonparametric Mann-Whitney U test. Fisher's Exact test was used for analysis of contingency tables. Relative risks (RR) were calculated with the approximation of Katz and given as the mean ( $95 \%$ confidence interval). A $P$ value $<0.05$ was considered to represent a statistically significant difference. All statistical analyses were done with GraphPad InStat version 3.10, GraphPad Software, San Diego, CA.

\section{Results}

In the period January 2007 to December 2009, a total of 1024 sinus radiography requests from the Institute for Tropical Diseases were screened to identify travelers eligible for inclusion. In total, 765 travelers fulfilled the inclusion criteria for this retrospective cohort study. Two-hundred and fifty-nine patients were excluded because they did not have a recent travel history or did not travel at all. The general characteristics of the 765 included patients are shown in Table 1. The male-to-female ratio was approximately $3: 2$. The median age of all travelers was 38 years and ranged from 11 to 75 years. One-hundred and sixty-five (22\%) of 765 ill returned travelers had abnormal sinus radiography. More than half of the abnormal radiographic findings comprised mucosal membrane thickening of the sinuses, and the sinus abnormalities are detailed in Table 2. There were no significant differences in age, travel destination, duration of travel, or laboratory findings between ill returned travelers with radiographic abnormalities and those without. Males were more likely to have abnormal sinus radiography than females (RR 1.6 [95\% confidence interval 1.2-2.2]). Interestingly, of the upper respiratory tract symptoms, fever, cough, headache, malaise, and the common cold, only the common cold was found to be present more frequently in travelers with abnormal sinus radiography (RR 2.4 [1.9-3.2]), whereas more than half of the travelers with abnormal sinus radiography had no upper respiratory tract symptoms at admission. Travelers with abnormal sinus radiography were more likely to receive nasal decongestants (RR 18.2 [9.4-35.1]) but not antibiotics. Travelers who presented with symptoms of the common cold were more likely to receive nasal decongestants (RR 5.0 [3.2-8.0]) than travelers without these symptoms.

\section{Discussion}

This retrospective cohort study covering a three-year observation period revealed that only one in five of 765 ill returned travelers had abnormal sinus radiography. More than half of the abnormal radiographic findings comprised mucosal membrane thickening of the sinuses. Interestingly, in a metaanalysis, it was shown that the radiographic criterion "fluid or opacity" increased the post-test probability of sinusitis to $78 \%$, while a negative radiograph would decrease it to $25 \%{ }^{7}$ Adding the criterion "mucus membrane thickening" induced imprecision to the estimate of the specificity of radiography for the diagnosis of acute rhinosinusitis. ${ }^{7}$ In our study "mucous membrane thickening" comprised 
Table I General characteristics of patients in relation to findings of sinus radiography

\begin{tabular}{|c|c|c|c|c|c|}
\hline & $\begin{array}{l}\text { Total } \\
n=765(100 \%)\end{array}$ & $\begin{array}{l}\text { Abnormal sinus radiography } \\
n=165(22 \%)\end{array}$ & $\begin{array}{l}\text { Normal sinus radiography } \\
n=600(78 \%)\end{array}$ & $P$ value & $\begin{array}{l}\text { Relative risk } \\
{[95 \% \mathrm{CI}]}\end{array}$ \\
\hline \multicolumn{6}{|l|}{ Gender } \\
\hline Male & 453 (59) & $116(70)$ & $337(56)$ & 0.0012 & $1.6[1.2-2.2]$ \\
\hline Female & $312(4 \mid)$ & $49(30)$ & $263(44)$ & & \\
\hline Age (years) & $38(\mathrm{II}-75)$ & $4 \mathrm{I}(16-75)$ & $37(11-75)$ & & \\
\hline \multicolumn{6}{|l|}{ Destination } \\
\hline Africa & $358(47)$ & $81(49)$ & $277(46)$ & n.s. & \\
\hline Asia & $258(34)$ & $50(30)$ & $208(35)$ & n.s. & \\
\hline North America & II (I) & $4(2)$ & $7(I)$ & n.s. & \\
\hline South America & $123(16)$ & $28(17)$ & $95(16)$ & n.s. & \\
\hline Europe & $9(1)$ & I (I) & $8(1)$ & n.s. & \\
\hline Oceania & $6(1)$ & $\mathrm{I}(\mathrm{I})$ & $5(1)$ & n.s. & \\
\hline Duration travel (days) & $21(1-575)$ & $2 I(I-348)$ & $21(2-575)$ & n.s. & \\
\hline \multicolumn{6}{|l|}{ Symptoms/signs } \\
\hline Fever & $258(34)$ & $53(32)$ & $205(34)$ & n.s. & \\
\hline Common cold & $110(14)$ & $48(29)$ & $62(10)$ & $<0.0001$ & $2.4[1.9-3.2]$ \\
\hline Cough & $226(30)$ & $57(35)$ & $169(28)$ & n.s. & \\
\hline Headache & $34 I(45)$ & $80(48)$ & $261(44)$ & n.s. & \\
\hline Malaise & 401 (52) & $84(5 \mathrm{I})$ & $317(53)$ & n.s. & \\
\hline Fever $\left(\geq 38^{\circ} \mathrm{C}\right)$ & $258(34)$ & $53(32)$ & $205(34)$ & n.s. & \\
\hline \multicolumn{6}{|l|}{ Laboratory findings } \\
\hline ESR (mm/hour) & $13(1-137)$ & $14(1-128)$ & $12(1-137)$ & n.s. & \\
\hline Leukocytes (×109/L) & $6.8(0.5-26.7)$ & $6.8(1.9-22.1)$ & $6.9(0.5-26.7)$ & n.s. & \\
\hline CRP (mg/L) & $16(1-605)$ & $21(I-453)$ & $14(1-605)$ & n.s. & \\
\hline
\end{tabular}

Note: Data are given as median (range) or as a proportion, ie, $\mathrm{n}(\%)$.

Abbreviations: $n$.s. not significant; $\mathrm{Cl}$, confidence interval; CRP, C-reactive protein; ESR, erythrocyte sedimentation rate.

almost $60 \%$ of the sinus abnormalities found. Exclusion of this criterion for the diagnosis of acute rhinosinusitis might decrease this diagnostic imprecision but, on the other hand, it would also significantly affect the diagnostic yield of sinus radiography.

In fact, the findings of the present study challenge the view that sinus radiography is a helpful tool to diagnose acute rhinosinusitis in ill returned travelers. Approximately five ill returned travelers need to undergo sinus radiography to diagnose one case of acute rhinosinusitis in ill returned travelers.

Table 2 Description of abnormal findings on sinus radiography in 165 of 765 ill returned travelers

\begin{tabular}{llll}
\hline Maxillary sinus & Left & Right & Total \\
\hline Mucosal thickening & 62 & 83 & 145 \\
(Sub)total opacity & 25 & 16 & 41 \\
Fluid level & 18 & 12 & 30 \\
Opacity + fluid level & & 1 & 1 \\
Other & & 2 & 2 \\
Ethmoidal sinus & & \\
(Sub)total opacity & & 19 \\
Frontal sinus & & \\
Fluid level & & 1 \\
(Sub)total opacity & & 5 \\
Total & & & 244 \\
\hline
\end{tabular}

These figures may even be worse (sinus radiography needed in 14 ill returned travelers to diagnose one case of acute sinusitis) when "opacity" and "fluid level" were considered as the only radiographic hallmarks of acute rhinosinusitis. In addition, the clinical consequence of an abnormal sinus radiograph in this study was limited to whether or not nasal decongestants were prescribed for the ill-returned traveler. Even though patients with abnormal sinus radiography were 18 times more likely to receive nasal decongestants than patients with normal sinus radiography, the prescription of antibiotics was not significantly related to the findings of sinus radiography; this latter finding is in line with several guidelines for the management of acute rhinosinusitis. ${ }^{1,2,4}$ Interestingly, a substantial proportion of the patients with abnormal sinus radiography also presented with the complaint of "common cold". Of course, this symptom is far easier to identify than abnormal sinus radiography, but from a clinical point of view, it is also a relevant symptom because its presence was associated with a five-fold increase in the likelihood of receiving a nasal decongestant.

Moreover, it should be borne in mind that more than half of the travelers with abnormal sinus radiography (including those with mucous membrane thickening) had no upper 
respiratory tract symptoms at all on admission, which seriously questions the clinical relevance of abnormal radiographic sinus findings for the diagnosis of acute sinusitis in our hospital-based setting. Together with the observation that acute rhinosinusitis usually runs an uncomplicated and self-limiting course, ${ }^{8}$ it seems hard to find valid arguments to maintain sinus radiography in the diagnostic work-up of ill returned travelers. Additional benefits of the exclusion of sinus radiography may relate to prevention of unnecessary radiation, in particular to the eye lens and thyroid gland, as well as significant reduction in costs, estimated to total up to an annual reduction of costs of $€ 11.000$ (approximately $€ 44$ per sinus radiograph series).

In conclusion, the results of this retrospective cohort study indicate that there is no additional benefit of routine sinus radiography in the diagnostic work-up of ill returned travelers.

\section{Disclosure}

The authors report no conflicts of interest in this work.

\section{References}

1. Dutch NHG standard for rhinosinusitis. Available at: http://www.nhg. artsennet.nl/kenniscentrum. Accessed March 18, 2011.

2. Van Buchem FL, Knottnerus JA, Schrijnemaekers VJ, et al. Primary-carebased randomised placebo-controlled trial of antibiotic treatment in acute maxillary sinusitis. Lancet. 1997;349:683-687.

3. Stalman W, van Essen GA, van der Graaf Y, et al. Maxillary sinusitis in adults: An evaluation of placebo-controlled double-blind trials. Fam Pract. 1997;14:124-129.

4. Lindbaek M, Hjortdahl P. The clinical diagnosis of acute purulent sinusitis in general practice - a review. Br J Gen Pract. 2002;52:491-495.

5. Varonen H, Mäkelä M, Savolainen S, et al. Comparison of ultrasound, radiography, and clinical examination in the diagnosis of acute maxillary sinusitis: A systematic review. J Clin Epidemiol. 2000;53:940-948.

6. Freedman DO, Weld LH, Kozarsky PE, et al. Spectrum of disease and relation to place of exposure among ill returned travellers. N Engl J Med. 2006;354:119-130.

7. Engels EA, Terrin N, Barza M, et al. Meta-analysis of diagnostic tests for acute sinusitis. J Clin Epidemiol. 2000;53:852-862.

8. Stalman WA, van Essen GA, van der GraafY. Determinants for the course of acute sinusitis in adult general practice patients. Postgrad Med J. 2001;77:778-782.

\section{Publish your work in this journal}

The International Journal of General Medicine is an international, peer-reviewed open-access journal that focuses on general and internal medicine, pathogenesis, epidemiology, diagnosis, monitoring and treatment protocols. The journal is characterized by the rapid reporting of reviews, original research and clinical studies across all disease areas.
A key focus is the elucidation of disease processes and management protocols resulting in improved outcomes for the patient. The manuscript management system is completely online and includes a very quick and fair peer-review system. Visit http://www.dovepress.com/ testimonials.php to read real quotes from published authors. 